\section{Gerenciamento da Visitação em Áreas \\ Naturais: considerações sobre a aplicação do método VAMP ao Parque Estadual de Campos do jordão - SP, Brasil}

Visitor Manaement in Natural Areas: considerations about the VAMP method at Campos do Jordão State Park - SP, Brazil

Beatriz Veroneze Stigliano Pedro de Alcântara Bittencourt César ${ }^{2}$

RESUMO: Este trabalho traz reflexōes sobre um dos principais métodos de gerenciamento da visitação em áreas naturais, o Processo de Gerenciamento da Visitação-VAMP. Apresentam-se suas principais características e seus objetivos, bem como considerações sobre sua aplicação ao Parque Estadual de Campos do Jordão - PECJ. Efetua-se, a seguir, uma análise sobre suas potencialidades.

PALAVRAS-CHAVE: turismo na natureza; unidades de conservação; Processo de Gerenciamento da Visitação - VAMP; Parque Estadual de Campos do Jordão - PECJ.

ABSTRACT: This study introduces considerations on one of the most important existing visitor management methods focusing on natural areas, the Visitor Activity Management Process - VAMP. Its main features and purposes are presented, as well as considerations regarding its use at the Campos do Jordão State Park. Its potentials are then analysed.

KEYWORDS: tourism in natural areas; protected areas; Visitor Activity Management Process - VAMP; Campos do Jordão State Park - PECJ.

1. Bacharel e mestre em Turismo, pela ECA-USP; mestre em Leisure and Environments, pelo programa WICE, da World Leisure and Recreation Association - WAU; doutoranda pelo PROCAM-USP; docente e coordenadora do Curso de Turismo da UFScar. Contato: Rua Monte Alegre, 58/73 - 05014-000 - São Paulo-sP; e-mail: biatur@usp.br.

2. Arquiteto, pela UNITAl; especialista em Planejamento e Marketing Turístico, pelo SENAC; mestre em Turismo, pelo UNIBERO; doutorando em Geografia, pela FFLCH-USP. Coordenador da Pós-Graduação em Turismo, do Centro Universitário Belas-Artes. Contato: Rua Monte Alegre, 58/73 - 05014-000 - São Paulo - sp;e-mail: pedrotur@usp.br.

\section{Introdução}

Verifica-se que a crescente procura por atividades de lazer em áreas naturais vem gerando novos desafios aos encarregados pelo gerenciamento das localidades visitadas. Busca-se, na análise da visitação, encontrar referenciais teórico-práticos para que as atividades de lazer atendam aos diversos anseios dos atores envolvidos.

Apesar de certos questionamentos com relação ao nível de coexistência que pode ser atingido entre a conservação e o lazer em áreas naturais, especialmente as unidades de conservação (UCs), há esforços na busca por encontrar estratégias para minimizar os impactos que este uso pode causar, ou acelerar, bem como para o gerenciamento da visitação. Pesquisadores de países como Estados Unidos, Canadá e Austrália, principalmente, objetivando contribuir com os estudos sobre o tema, vêm criando e aprimorando métodos como os seguintes: Espectro de Oportunidades Recreativas - ROS; Limites Aceitáveis de Mudança - LAC; Gerenciamento de Impactos da Visitação - VIM; Proteção à Experiência do Visitante e aos Recursos - VERP; Processo de Gerenciamento da Visitação - VAMP; e Modelo de Otimização do Gerenciamento Turístico - TOMM.

O gerenciamento da visitação é uma forma de se contribuir para a conservação dos recursos e a organização do uso público em áreas naturais, e constitui-se de um amplo leque de instrumentos a serem estabelecidos e implantados.

Neste trabalho, apresentam-se as principais características e os objetivos do VAMP, além de considerações relacionadas à aplicação do método ao Parque Estadual de Campos do Jordão (PECJ), com a discussão sobre suas potencialidades.

\section{0 método VAMP}

A partir de meados da década de 1980, críticas internas e externas convenceram a equipe do Canadian Park Service - CPS, responsável pelas áreas protegidas do Canadá, de que serviços de interpretação e de visitação em áreas naturais teriam que ser conduzidos de forma a se contemplarem aspectos administrativos de gestão e de conservação da natureza, uma vez que estas áreas vinham sendo amplamente inseridas no mercado turístico (Graham, 1990). Tal situação levou o CPS a desenvolver, junto a consultores de áreas afins, o método VAMP.

Este método consiste de uma estrutura baseada em hierarquia de decisões no âmbito de um programa de gerenciamento. Decisões para o plano administrativo referem-se à seleção e à criação de oportunidades para os visitantes usufruírem a área, através de atividades educativas e recreativas. O método enfatiza, dessa forma, a interpretação ambiental e os serviços oferecidos. 
O VAMP é uma técnica proativa e flexível, visando à tomada de decisões, a ser aplicada conjuntamente pelos atores envolvidos, contribuindo para uma abordagem mais integrada no gerenciamento de áreas naturais. Traz a perspectiva de desenvolver um sistema de informações sobre os diversos usuários, utilizando recursos das Ciências Sociais e Biológicas, conjuntamente, para a deliberação sobre o acesso às áreas em questão, bem como os tipos de uso (Parks Canada, 1991).

Fatores considerados no desenvolvimento do método incluem, principalmente, a caracterização das atividades desenvolvidas por visitantes (os tipos, a quantidade, a diversidade e a localização); as experiências e os benefícios procurados; os serviços complementares e as estruturas requeridas; o perfil dos envolvidos; os valores e a sensibilidade dos recursos; a legislação existente, as políticas, o direcionamento administrativo, os planos, a oferta local de serviços e facilidades; a oferta regional de atividades/serviços; a satisfação quanto à oferta (Wearing \& Neal, 1999).

\section{Caracterização do Parque Estadual de Campos do Jordão - PEC]}

O Parque Estadual de Campos do Jordão - PECJ localiza-se no município de mesmo nome, situado a leste do Estado de São Paulo, no alto da Serra da Mantiqueira.

O município apresenta sobreposição de três Áreas de Proteção Ambiental (APAS) - uma federal (Leis nํㅜ 6.902 e n⿳ำ 6.938, Decreto Federal nº 91.304); uma estadual (Lei no 7.438/91, Decreto Estadual no 47.400/02) e, também, uma APA municipal (Lei $\mathrm{n}^{\circ}$ 1.484/85, Decreto Municipal no 1.850/88). Tem características do clima tropical de altitude (Modenesi, 1984), o que faz com que apresente uma oferta diferenciada de muitas áreas brasileiras onde predomina o clima tropical.

O PECJ dista cerca de 14 quilômetros do centro do município, sendo o acesso em pista asfaltada e bem sinalizada. Esta UC, mais conhecida como Horto Florestal, foi criada em 27 de março de 1941, para resguardar os últimos remanescentes das matas de araucária e demais espécies vegetais da região (PECJ, 2002). Para o estabelecimento desta UC, foram desapropriados, inicialmente, $2.887,60$ hectares. Outras desapropriações foram realizadas, posteriormente, resultando nos atuais 8.341 hectares. A UC abrange, hoje, cerca de um terço do Município de Campos do Jordão.

A administração deste Parque é de responsabilidade do Instituto Florestal, órgão da Secretaria do Meio Ambiente do Estado de São Paulo. Por se tratar de um Parque Estadual, tem, segundo o Sistema Nacional de Unidades de Conservação - SNUC, como objetivo central, preservar ecossistemas naturais e possibilitar a realização de pesquisas científicas, o desenvolvimento de atividades de educação e de interpretação ambiental, de recreação em contato com a natureza e de turismo ecológico (Ministério do Meio Ambiente, 2003).

No que se refere à vegetação do PECJ, esta é formada, principalmente, por mata de araucária e podocarpus, campos, capoeiras, samambaial, vegetação aquática e de brejos (Seibert et al., 1975).

Tem fauna variada, composta, principalmente, por mamíferos de pequeno e médio porte, como bugio, caitetu, cotia, quati, esquilo, macaco prego, veado catingueiro, onça sussuarana e queixada, entre outros, além de inúmeras espécies de aves, como jacu, nhambu, papagaio, sabiá, macuco, tangará, azulão, codorna beija-flor, curiango, tuim, coruja, perdiz e siriema, entre outras. No PECJ, são encontradas, também, pelo menos 14 espécies de abelhas e vespas, e dez espécies de ofídios. O peixe natural dos rios locais é o lambari, tendo sido, posteriormente, introduzida a truta arco-íris (Seibert et al., 1975).

$\mathrm{Na}$ área do parque denominada Área de Desenvolvimento, conforme Plano de Manejo desta UC, ${ }^{3}$ há infra-estrutura básica (abastecimento de água, energia elétrica, telefonia etc.), edificações voltadas à administração e equipamentos para a recepção dos visitantes, além de atrativos. Dentre os principais equipamentos, estão o centro de visitação, restaurante, lojas de artesanato e área de piquenique; já os atrativos são o centro de exposições, playground, passeio no "trenzinho", desenvolvimento de esportes de aventura, como tirolesa, a serraria, as trilhas, o viveiro de mudas e o orquidário.

\section{Análise da aplicação do método VAMP ao PECJ}

O método VAMP, forte instrumento administrativo, tem como objetivo o gerenciamento da visitação, visando à oferta harmônica de atividades de lazer e educativas, buscando, na análise dos visitantes, importantes subsídios para seu desenvolvimento.

Nos procedimentos do método VAMP, faz parte o levantamento de dados primários e secundários sobre a área analisada, baseando-se, principalmente, no Plano de Manejo, na legislação ambiental vigente, na realização do inventário do local, análise das interfaces com o entorno e dos visitantes, apresentando amplas possibilidades de reflexão, envolvendo um abrangente leque de técnicas de pesquisa, como a observação, a aplicação de entrevistas e questionários, entre outras.

3. O documento data de 1975 , não tendo sido efetuadas atualizaçōes.

4. Conforme dados fornecidos em entrevista pela Administraçāo do PECJ, visitaram o parque, no mês de julho de 2002, 29.397 pessoas, o que o posiciona como uma das UCS mais visitadas do Estado de São Paulo. 
De acordo com os procedimentos propostos pelo método VAMP (Canadian Parks Service, 1989), conduziu-se sua aplicação ao PECJ. Além das análises das fontes primárias, tendo, como principal subsídio, o Plano de Manejo da UC, foram aplicados 144 questionários a visitantes do PECJ, em julho de 2003, como um recurso auxiliar às análises, por se tratar de um estudo exploratório (Gil, 1987; Dencker \& Da Viá, 2001). Apresenta-se, a seguir, uma síntese das análises realizadas, baseando-se nas diversas fontes utilizadas.

Com relação ao perfil dos visitantes, estes, em geral, possuem nível superior de escolaridade, têm situação profissional estável e idade entre 21 e 50 anos. Todas as variáveis observadas indicam que estão, em geral, satisfeitos com os atrativos e serviços que encontram. Os visitantes são, em sua maioria, provenientes de municípios da porção leste do Estado de São Paulo, num raio que abrange o Município de São Paulo. Mostram-se muito interessados em atividades não diretamente ligadas à natureza, como a compra de artesanato. O Centro de Visitação é, atualmente, subutilizado. Existe interesse no engajamento em atividades monitoradas, indicando a necessidade de uma possível adequação da oferta de atividades por parte do Parque.

Ainda quanto aos atrativos, há necessidade de melhorar a comunicação visual, provavelmente com o aumento do número de placas, bem como a tradução das informações para outros idiomas, além da oferta de folders e mapas.

Com relação à oferta regular de atividades interpretativas e de educação ambiental na UC, há uma oportunidade, consolidada com a presença de estagiários, que atuam no PECJ nos meses de maior demanda de visitantes, que coincidem com as férias escolares, oferecendo atividades organizadas, relacionando-se ativamente com os visitantes. Deve-se atentar para as opções de lazer para os adultos, por constituírem grande parte do público do PECJ.

Observou-se a necessidade de avaliação dos serviços voltados à terceira idade, segmento crescente da sociedade brasileira. Uma possibilidade seria oferecer opções de caminhos com alta acessibilidade, a serem utilizados por idosos e pessoas com dificuldade de locomoção, ampliando o espectro de abrangência de visitantes.

Analisando-se o uso dos atrativos e estruturas do PECJ, verifica-se que maior atenção deve ser direcionada à recepção do visitante no Parque, em seu primeiro contato, de forma que o conhecimento do conjunto das possibilidades recreativas e educativas da UC seja efetivo.

Uma proposta que deve ser considerada pela administração é a criação de um Centro de Interpretação, juntamente com o desenvolvimento de uma campanha regular de educação ambiental, que possa ser utilizada como estratégia de conscientização dos visitantes e moradores locais acerca de questões ambientais relevantes.

\section{Considerações finais}

O método VAMP apresenta enfoque voltado a aspectos sociais da visitação em áreas naturais. Não objetiva, diretamente, o levantamento das condições físicas do ambiente natural, mas leva em consideração a necessidade de sua preservação para a composição da oferta ao visitante e para a manutenção da integridade da área.

$O$ VAMP promove o entendimento do visitante e de sua relação com o local visitado, fornecendo a possibilidade de, assim, adequar a oferta de serviços e atividades, de forma a proporcionar experiências satisfatórias.

Ressalta-se, neste processo, a necessidade de uma atuação conjunta de profissionais das diversas áreas, contribuindo para a solução do dilema lazer-conservação em suas inúmeras facetas. Além disso, cada área tem suas características e peculiaridades, e o VAMP (bem como os demais métodos) deve ser visto como um recurso para o planejamento e desenvolvimento da atividade de visitação, passível de adaptações. Desta forma, é necessário o amplo domínio das possibilidades oferecidas, para, juntamente com o conhecimento da localidade em questão, serem efetuadas as adequações pertinentes, quando necessárias.

Sobre o PECJ, este oferece um conjunto de possibilidades recreativas e educativas, de acordo, em grande parte, com o previsto pelo Plano de Manejo, que, no entanto, necessita de urgente atualização.

Este Parque tem um valor agregado muito forte como espaço de lazer. Para atingir seus objetivos como uma uc, entretanto, que tem como uma de suas funções propagar conhecimentos ambientais, é necessário desenvolver ações corretivas. Estas ações dizem respeito à oferta de atividades recreativas e educacionais orientadas e guiadas, direcionadas ao fornecimento de informações sobre o local e de atividades de interpretação ambiental.

Acredita-se, por fim, que o uso de métodos como o VAMP, em especial, poderá trazer grandes contribuições para o gerenciamento da visitação em áreas naturais brasileiras, em um esforço cujos resultados positivos se farão visíveis, em vários âmbitos, em médio e longo prazos.

\section{Referências bibliográficas}

CANADIAN PARKS SERVICE. 1989. Getting started: a guide to park service planning. Canada: Canadian Parks Service.

DENCKER, A. \& DA VIÁ, S. 2001. Pesquisa empírica em ciências humanas (com ênfase em comunicaçāo), Sāo Paulo: Futura.

GIL, A. C. 1987. Métodos e técnicas de pesquisa social. São Paulo: Atlas.

GRAHAM, R. 1990. Visitor management in Canada's National Parks. In: GRAHAM, R.E. \& LAWRENCE, R. (Eds.). Towards serving visitors and managing our resources: proceedings of a North American workshop 
on visitor management in parks and protected areas. Waterloo/Ottawa: Tourism Research and Education Center: University of Waterloo and Environment Canada/Canadian Parks Service. p. 271-298.

MINISTÉRIO DO MEIO AMBIENTE. SNUC - Sistema Nacional de Unidades de Conservaçāo. Disponível em: <http://www.mma.gov.br/port/sbf/dap/doc/snuc.pdf >. Acesso em: 13 jun. 2007.

MODENESI, M. C. 1984. 177 f. Significado dos depósitos correlativos quaternários em Campos do Jordāo - São Paulo: implicaçōes paleoclimáticas e paleoecológicas. Tese (Doutorado em Geografia)

São Paulo.

PARKS CANADA. 1991. Visitor activity concept. Ottawa, Canada: Parks Canada.

PECJ/SECRETARIA DO MEIO AMBIENTE DO ESTADO DE SÃO PAULO - SEMA. 2002. Folder do Parque Estadual Campos do Jordāo. São Paulo.

SEIBERT, P. et al. 1975. Plano de Manejo do Parque Estadual Campos do Jordāo. São Paulo: Secretaria da Agricultura, Instituto Florestal.

STIGLIANO, B. V. 2004. Visitantes em Unidades de Conservaçāo: o método vamp aplicado ao Parque Estadual de Campos do Jordāo (SP). Dissertação (Mestrado em Ciências da Comunicação) - ECA-USP, São Paulo.

WEARING, S. \& NEIL, J. 1999. Ecotourism: impacts, potentials and possibilities. Oxford: ButterwothHeinemann.

Recebido em: 30/07/2005.

Aprovado em: 27/06/2006. 